Egyptian

Orthodontic Journal

\title{
EFFECT OF VARIOUS PORCELAIN SURFACE TREATMENT METHODS ON SHEAR BOND STRENGTH OF ORTHODONTIC ADHESIVE
}

\author{
Ayman M. Eissa ${ }^{1}$, Walid E. Refaat ${ }^{2}$, and Sherif S. Morcos ${ }^{3}$
}

\section{ABSTRACT:}

Objective: to evaluate the effect of different treatment methods of porcelain surfaces before 6onding on the shear bond strength of orthodontic adhesive. Material and methods: This study was conducted on a sample of sixty feldspathic porcelain cylinders stored in artificial saliva for a week. The sample was divided into five equal groups twelve each according to the applied surface treatment, Gp1 diamond bur roughening, and Gp2 etching 37\% phosphoric acid GP3 Laser etching Gp4 9\% hydrofluoric acid etching Gp5 sand6lasting 50 micron aluminum oxide particles. Randomly one specimen from each group was scanned by electron microscope while the other specimens were bonded to metal brackets and stored in artificial saliva for one week then mounted in acrylic 6locks to allow measuring the shear bond strength using Instron universal testing machine. Results: Diamond bur group showed significant difference with all other groups. There is significant difference between phosphoric acid and laser on one hand and sand blasting and hydrofluoric on the other hand. But for 6oth phosphoric acid and laser groups there is no significant difference and for 6oth sand 6lasting and

1 - Candidate, Masters Degree Program, Orthodontic dept., Faculty of Dentistry, Suez Canal University.

2 - Assistant Professor, Orthodontic dept., Faculty of Dentistry, Suez Canal University.

3 - lecturer, Orthodontic dept., Faculty of Dentistry, Suez Canal University 
Egyptian

Orthodontic Journal

hydrofluoric acid groups there is no significant difference. Conclusion: The diamond bur group showed the highest bond strength, while phosphoric acid showed the least one.

Keywords: Shear bond strength. Laser. Orthodontic brackets.

\section{INTRODUCTION}

With the increased awareness of facial esthetics and growing dental contribution to this esthetics, the demand for orthodontic treatment in grown-ups has increased rapidly in the last decade ${ }^{[1,2]}$. Consequently, orthodontists are confronted with bonding to various esthetic prosthetic restorations including porcelain crowns. In these cases, bands cannot be used anymore for esthetic reasons. In such situations, bonding option looked like the solution but seemed as double edged weapon. On one hand, bond strength must be strong enough to resist forces applied by orthodontic appliances, oral function and mastication thus, avoid bond failure during treatment. On the other hand, porcelain restoration should be restored to its original glory after bracket removal.

Since porcelain surfaces are resistant to conventional acid etching, thus, surface modification is necessary to improve adhesion and retention of orthodontic appliances ${ }^{[3]}$.

Several methods have been suggested to prepare porcelain surfaces in order to acquire sufficient bond strength to orthodontic brackets. Among these techniques were etching porcelain with hydrofluoric acid, roughening porcelain with diamond burs, and sandblasting ${ }^{[4-6]}$.

In recent years, there has been a growing interest in laser applications in medical and dental fields. In the last decade, there has been an innovation in utilizing the Nd: YAG Laser to prepare the enamel surfaces for direct bonding of orthodontic attachments ${ }^{[7-9]}$ and also in roughening the porcelain surface before luting with hybrid resin cement ${ }^{[10]}$

The aim of the study to evaluate different porcelain treatment methods to increase the shear bond strength without affecting porcelain surface after debonding ${ }^{[11]}$.

Volume 50 - December 2016 
Egyptian

Orthodontic Journal

\section{MATERIALS AND METHODS}

\section{Preparation of porcelain cylinders:}

Glazed feldspar porcelain was fabricated into flat cylinders of standardized size $(10 \mathrm{~mm}$ diameter and $2 \mathrm{~mm}$ thickness). The fabrication was done according to the manufacturer's instructions from body porcelain (VMK feldspathic porcelain bad. Germany) by means of stacking technique where vibration and blotting were made to aid condensation. The porcelain specimens were then baked in a special furnace at $950 \mathrm{c}^{\mathrm{o}}$ under vacuum (Vita vacuum 50, Zahan fabrique, Germany). Glazing of the porcelain surface was performed by applying a thin layer of vita porcelain and firing without vacuum at $950 \mathrm{c}^{0}$ for $4 \mathrm{~min}$. After fabrication of the glazed porcelain cylinders, all specimens were stored in artificial saliva at room temperature for a week.

\section{Surface preparation of porcelain:}

The sample was divided into five equal groups according to the applied surface treatment.

Group I: Mechanical roughening with fine diamond bur (Dentsply USA). A fine diamond bur number was used to deglaze and roughen the porcelain surface. This was accomplished by using a high speed hand piece with water cooling. The diamond bur was held with its shaft parallel to porcelain surface and was gently applied in one direction (from left to right) for one time only.

Group II: Etching 37\% phosphoric acid application. (Dental technologies USA) $37 \%$ phosphoric acid gel was applied to the glazed porcelain surface. The application procedure was carried out for two minutes after careful surface dryness using an air syringe. The porcelain surfaces were then cleaned with water spray and dried thoroughly.

Group III: Etching with Nd:YAG laser (Continuum,USA). The laser treatment was achieved by using Nd:YAG laser machine. A beam of 10.6 micro meter wavelength was delivered in a continues focus mode through a flexible tube, $1.2 \mathrm{~mm}$ in diameter. Laser energy was measured to be $150 \mathrm{mj} /$ pulse when the output power was adjusted to three watt within 3 minutes lasing time. 
Egyptian

Orthodontic Journal

Surface treatment was accomplished by applying laser at different spots on the porcelain surface at which orthodontic brackets were to be bonded.

Group IV: Roughening with sandblasting. Micro etching of the porcelain cylinders with sand blaster with $50 \mu \mathrm{Al}_{2} \mathrm{O}_{3}$ (strahimittel 1594-1205 Germany) particles for 5 seconds at 100 psi was applied to the glazed surfaces through a nozzle at a distance $10 \mathrm{~mm}$. The porcelain surfaces were then cleaned with water spray and dried thoroughly.

Group V: Etching with 9\% Hydrofluoric acid (Ultradent USA). Using air syringe, the specimens in this group were air dried before any acid application. 9\% hydrofluoric acid gel was applied in the glazed porcelain surface for $90 \mathrm{sec}$ according to the manufacturer's instructions. After completion of etching, the specimens were rinsed copiously with water and thoroughly dried.

Scanning of the prepared porcelain cylinders.

After the completion of the five different surface treatments one porcelain cylinder was randomly selected from each group. The specimens were glued to copper holder to enable the scanning procedure. The specimens were then coated with a thin film of gold in a sputtered coater (Edwards sputter coater s150.England)

The specimens were mounted in the Scanning Electron Microscope SEM (JEOL,JSM-20, Scanning Microscope Japan) operated at accelerating voltage of $19 \mathrm{KV}$ and had a resolution of 200A. The fine electron probe of the SEM scanned over the mounted specimen and the reflected secondary radiation was detected. After a process of magnification and amplification, the detected secondary radiation was monitored on the SEM screen. The center of the area of the disc was photographed using black and white film with original magnification X500.

\section{Bonding of orthodontic brackets to the porcelain cylinders}

After performing the scanning procedure and discarding one specimen from each group, the remaining sixty specimens were divided equally into five groups, then were rinsed with water spray in order to remove any debris from treated surfaces and air dried. One layer of silane coupling agent (Ultradent, USA) was applied on the treated porcelain surfaces with brush applicator and left to dry for one minute according to the manufacturer's instructions. 
Egyptian

Orthodontic Journal

Standard edgewise lower incisor stainless steel orthodontic brackets (Oramco USA) were used. The bracket base dimensions were $2.9 \mathrm{~mm}$ cervical width $3.3 \mathrm{~mm}$ incisal and $3.5 \mathrm{~mm}$ height. They were bonded to the treated porcelain cylinders by using light cured orthodontic composite where the bracket was positioned and pressed on the porcelain surface until fully seated excessive cement was removed later with explorer.

All porcelain cylinders with brackets bonded to them were stored in artificial saliva at room temperature for one week before testing the bond strength.

\section{Measuring the shear bond strength:}

A universal testing machine (Instron USA) was used to measure the bond strength. Each specimen was embedded in a cubic acrylic resin mold to enable mounting the specimens in a specialized jig attached to the base of the testing machine.

The acrylic blocks were mounted in such a way to allow positioning of the bonded brackets parallel to the direction of the load application, which was applied with a chisel at the interface between the bracket and the porcelain surface. The testing machine was adjusted to a crosshead speed of $0.5 \mathrm{~mm} /$ minute, until bond failure occurs. A piezoelectric sensor detected the force required to debond the computer software program. Such signals were interpreted and recorded electronically on a graph and measured in Newton. The force per unit area was calculated and reported as the shear bond strength in Mega Pascal, where the metal brackets $10.85 \mathrm{~mm}^{2}$.

\section{Evaluating the site of failure:}

Each specimen was examined visually to determine the location of failure site, as well as, the amount of adhesive left on the porcelain surface and the bracket base after debonding process. This was performed according to the adhesive Remnant Index (ARI) system this includes the following four scores:

Score 0: no adhesive on the surface

Score 1: less than half the adhesive on the surface. 
Egyptian

Orthodontic Journal

Score 2: more than half the adhesive on the surface.

Score3: the entire adhesive on the surface.

\section{STATISTICAL ANALYSIS}

The collected data was carried out using SPSS program (SPSS, 2008) to calculate mean, standard deviation, minimum and maximum for shear bond strength in Mega Pascal.

One way analysis of variance (SPSS, analyze, compare means, one way ANOVA) was used to test the effect of surface treatment on shear bond strength. Duncan Post-Hoc Multiple Comparisons (Post-Hoc) at $p \leq 0.05$ was used for means of comparison. $p \leq 0.05$

\section{RESULTS}

The Value of the mean shear bond strength was 9.88 Mega Pascal (MPa) for diamond bur which showed the highest shear bond strength. There was a significant difference between diamond bur group and other groups. For both phosphoric acid and laser groups there is no significant difference. There is no significant difference between hydrofluoric and sandblasting groups tabulated in table (1) shown in fig (1).

Table (1): Showing descriptive statistics and the test of significance for the effect of surface treatment on shear bond strength using metal bracket (in MPa).

\begin{tabular}{|lccccc|}
\hline \multicolumn{1}{|c}{ Treatment } & Mean & S.D. & Min. & Max. & dt \\
\hline Diamond bur & 9.888 & 1.261 & 7.71 & 11.32 & $\mathrm{a}$ \\
Phosphoric acid & 5.538 & 0.722 & 4.24 & 6.33 & $\mathrm{c}$ \\
Laser etching & 6.150 & 0.628 & 5.02 & 6.72 & $\mathrm{c}$ \\
Sandblasting & 8.188 & 1.437 & 6.69 & 10.24 & $\mathrm{~b}$ \\
Hydrofluoric acid & 7.498 & 1.280 & 6.26 & 9.60 & $\mathrm{~b}$ \\
\hline
\end{tabular}

S.D = Standard deviation

Dt $=$ Duncan's Multiple Range Test for the effect of treatment.

Means with the different letter within each column are significantly different at $\mathrm{p}=0.05$ 
Diamond bur group showed significant difference with all other groups. There is significant difference between phosphoric acid and laser on one hand and sand blasting and hydrofluoric on the other hand. But for both phosphoric acid and laser there is no significant difference and for both sand blasting and hydrofluoric acid groups there is no significant difference tabulated in table (1) shown in fig (1).
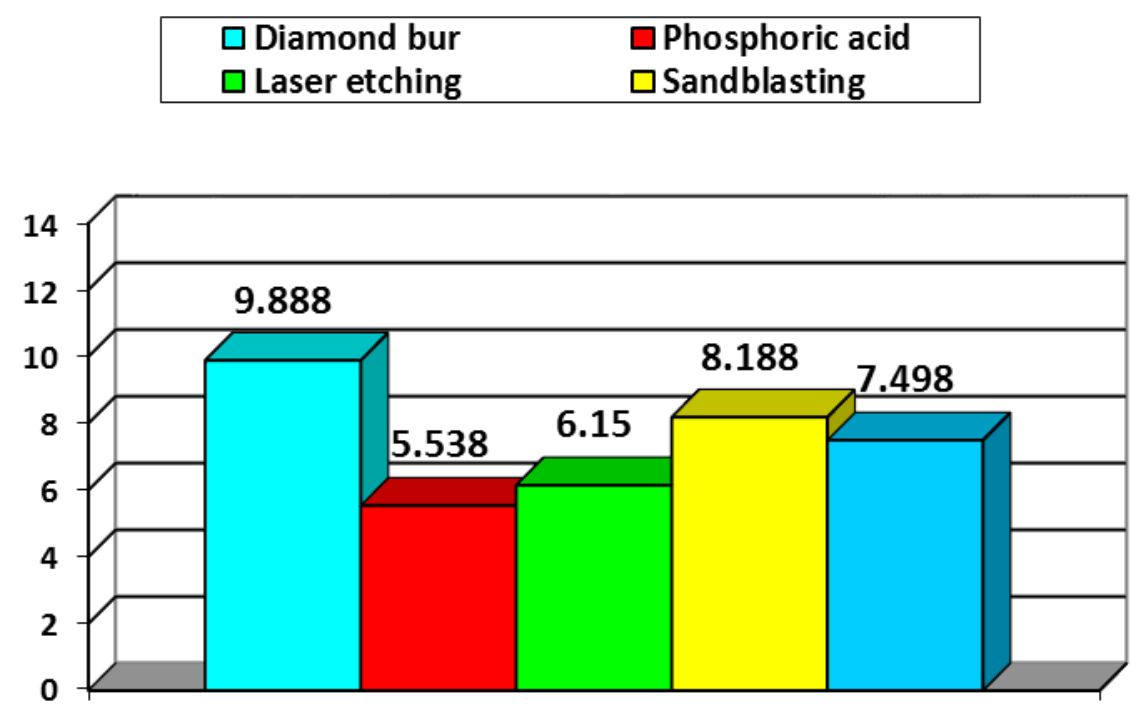

Figure (1): The histogram showing the effect of surface treatment on shear bond strength using ceramic bracket. (in MPa).

The highest value of porcelain fracture was observed in diamond bur group where $20 \%$ of the specimens were fractured during debonding procedure. While no fractured porcelain were recorded during debonding of laser and phosphoric groups.

Frequency of the adhesive Remnant index (ARI):

The highest of score 3 where the adhesive failure occurred between the bracket base and the composite resin was evident in $67 \%$ for porcelain surfaces in diamond bur group for porcelain surfaces with almost the entire composite was left on porcelain surface. It was followed by sand blasting and hydrofluoric acid. The mode of failure in laser and 
phosphoric acid groups was almost between the composite and the porcelain surface where score 0 and score 1 where manifested.

Table (2): Adhesive Remnant Index for the five methods of porcelain surface treatment of Metal bracket group.

\begin{tabular}{|l|c|c|c|c|c|}
\hline Group & $\mathrm{N}$ & Score 0 & Score 1 & Score 2 & Score 3 \\
\hline Diamond bur & 6 & 0 & 0 & $33 \%$ & $67 \%$ \\
Phosphoric acid & 6 & $60 \%$ & $40 \%$ & 0 & 0 \\
Laser & 6 & $55 \%$ & $25 \%$ & $10 \%$ & 0 \\
Hydrofluoric & 6 & 0 & $10 \%$ & $43 \%$ & $47 \%$ \\
Sandblasting acid & 6 & 0 & $10 \%$ & $35 \%$ & $55 \%$ \\
\hline
\end{tabular}

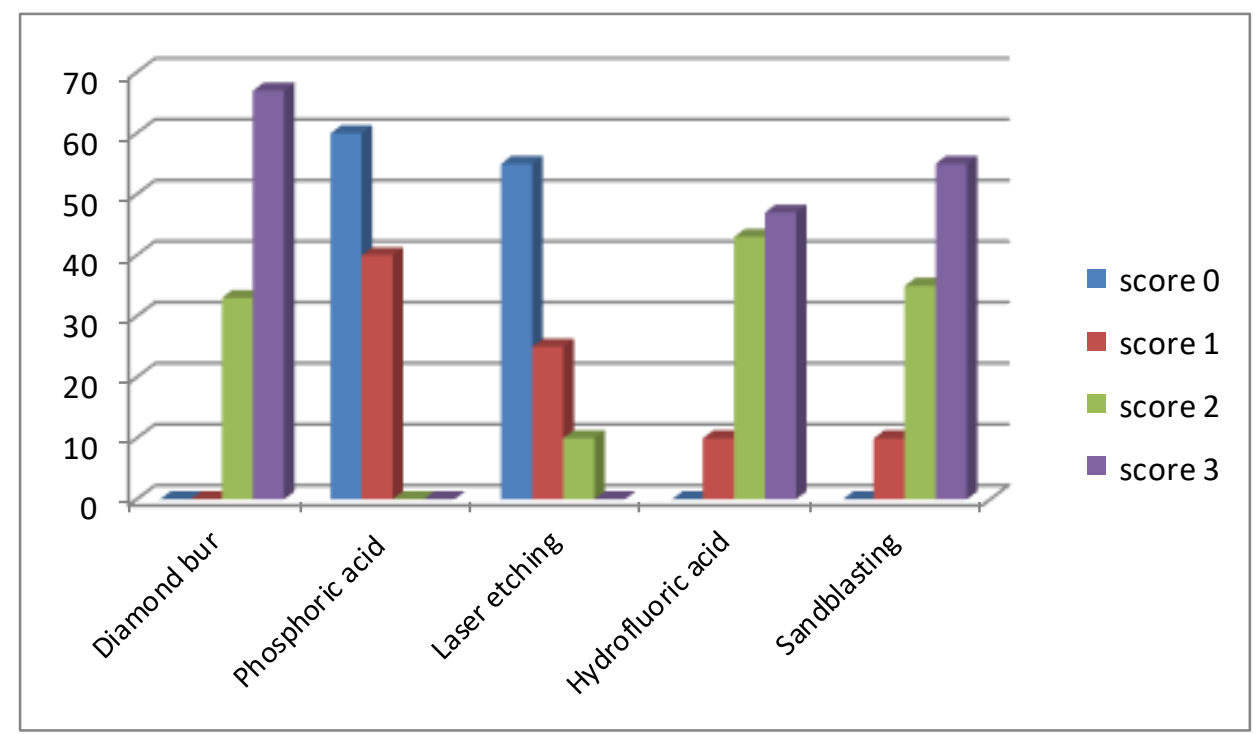

Figure (2) the histogram showing percentage of Adhesive Remnant Index for the five methods of porcelain surface treatment of Metal bracket group

$\mathrm{N}$ : Number

Score 0: No adhesive on the surface.

Score 1: less than half the adhesive on the surface.

Score 2: more than half the adhesive on the surface.

Score 3: the entire adhesive on the surface 
Egyptian

Orthodontic Journal

\section{Scanning Electron Microscope Evaluation:}

The scanning electron photomicrographs of the porcelain surfaces conditioned by various techniques as well as a glazed surface without any treatment were evaluated. In contrast to smooth appearance of the intact glazed porcelain fig (3), the conditioned surfaces showed different pictures.

Roughening with diamond bur showed surface erosion and irregularities in form of deep depressions shown in fig (4).

Phosphoric acid application produced no surface changes as shown in fig (5) while laser application showed shallow depressions as shown in fig (6).

Sandblasting showed an extensive irregularities in depth penetration of porcelain with numerous elevation and depressions as shown in fig (7).

Hydrofluoric acid etching produce a lot of elevations and depressions all over the surface as shown in fig (8). So among the five groups diamond bur roughening showed more depth penetration, followed by sandblasting and Hydrofluoric acid, while laser etching caused less surface indentation and finally the phosphoric acid application didn't produce any observable changes.

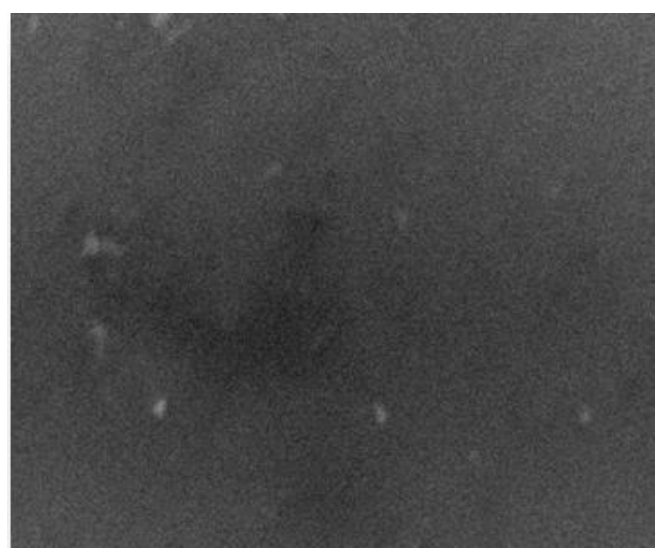

Figure (3) a scanning electron photomicrograph of the untreated porcelain surface showing normal surface appearance (magnification X500)

Volume 50 - December 2016 


\section{Egyptian}

Orthodontic Journal

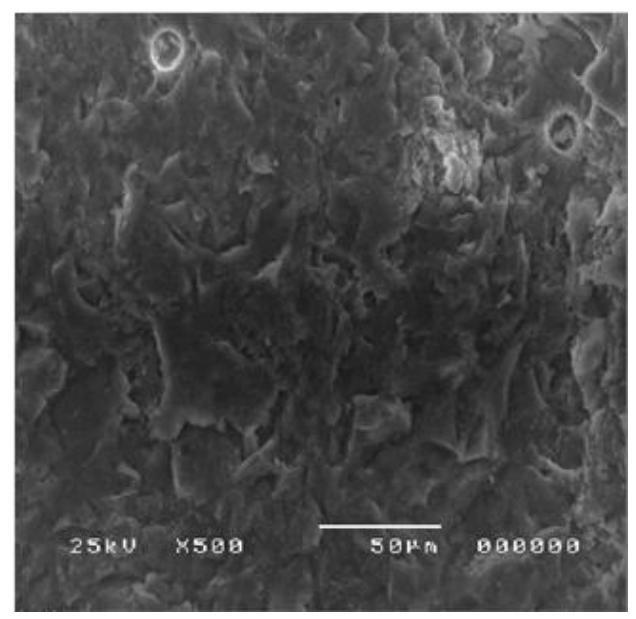

Figure (4) a scanning electron photomicrograph of the diamond bur treated porcelain surface showing surface roughness appearance (magnification X500).

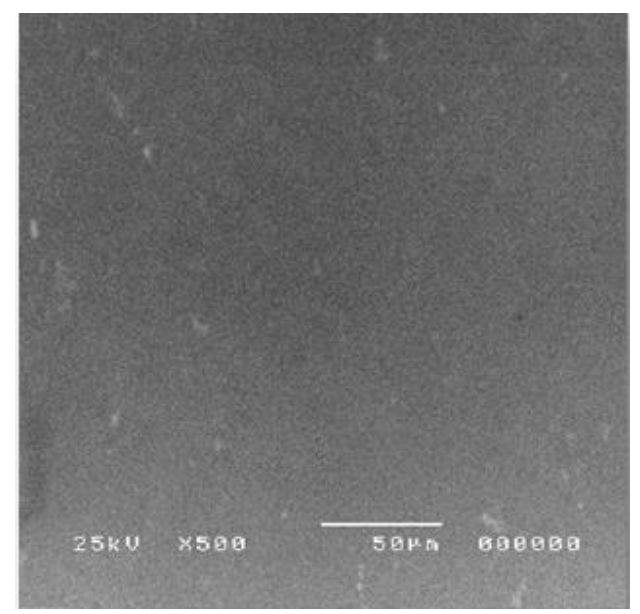

Figure (5) a scanning electron photomicrograph of the phosphoric acid treated porcelain surface showing surface appearance as if it is normal ( magnification X500). 


\section{Egyptian}

Orthodontic Journal

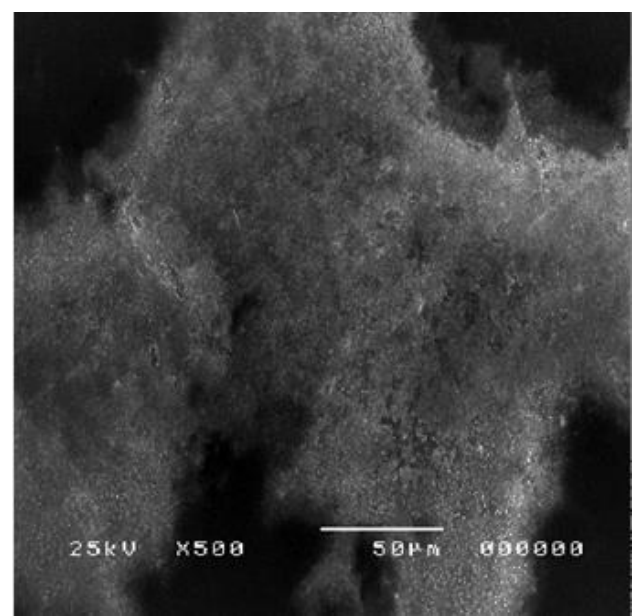

Figure (6) a scanning electron photomicrograph of the Lased porcelain surface showing surface irregularities (magnification X500).

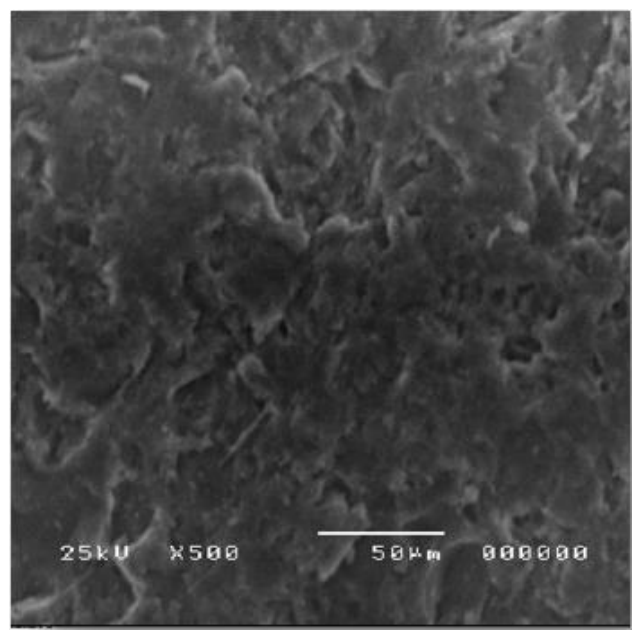

Figure (7) a scanning electron photomicrograph of the sandblasted porcelain surface showing surface roughness and irregularities. (magnification x500).

Volume 50-December 2016 


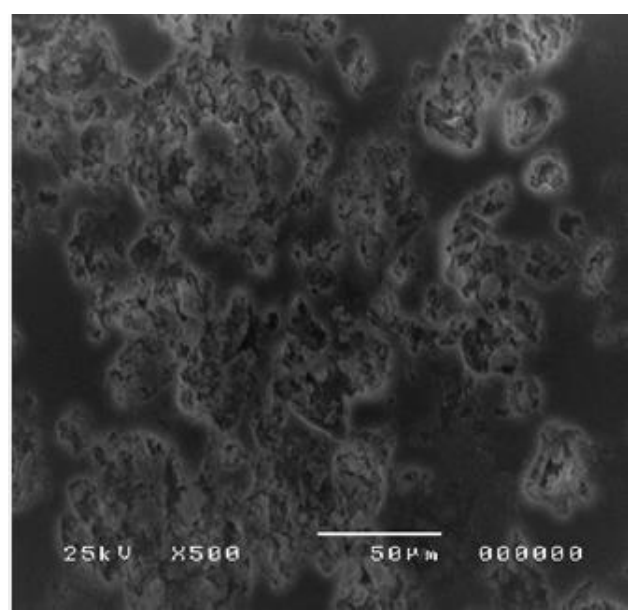

Figure (8) a scanning electron photomicrograph of the Hydrofluoric acid etching of porcelain surface showing numerous elevations and depressions all over the surface. (magnification X500).

\section{DISCUSSION}

The results of this study revealed a significant difference between diamond bur and other groups (table 1, fig.1).

There was no significant difference between neither sand blasting and hydrofluoric acid groups nor between laser and phosphoric acid groups (table 1, fig.1).

However there was significant difference between sand blasting surface treatment and both laser, and etching with $37 \%$ phosphoric acid. Also there was significant difference between etching with $9 \%$ hydrofluoric acid on one side and both laser and etching with $37 \%$ phosphoric acid on the other side.

Diamond bur roughened the porcelain surface producing a lot of channels and pores which increased the surface area for the adhesive increasing the bond strength obviously. The micromechanical sandblasting and the chemical etching with $9 \%$ hydrofluoric acid modified the surface texture resulting in increasing the shear bond 
Egyptian

Orthodontic Journal

strength of the orthodontic brackets. Similar results were documented by Suliman et al. (1993) $)^{[12]}$, Sant et al.(2002) $)^{[13]}$, Schmag et al (2003) ${ }^{[14]}$, Kassano et al (2003) ${ }^{[15]}$, Turk (2006) $\left.{ }^{[16}\right]$, Karan $(2007)^{[17]}$ and Rondell et al. $(2010)^{[18]}$. On the contrary, Katamish et al. (1993) ${ }^{[19]}$ and $\mathrm{Li}$, et al. $(2000)^{[20]}$, Kyung et al. $(2008)^{[21]}$ and Amal et al $(2012)^{[22]}$ found insignificant difference in bond strength between laser etching and hydrofluoric acid etching. This insignificant difference could be explained on the basis that deglazing of porcelain surface was done first before laser application which definitely increased the bond strength of silane/composite to the porcelain surface.

We found that the mean shear bond strength was 9.9 Mpa when using diamond bur surface treatment. This reflects the highest value of shear bond strength that exceeds the recommended acceptable clinical range of bond strength which was considered by Newman (1984) ${ }^{[23]}$ and Ewoldsen et al. (1995) ${ }^{[24]}$ to be $2.8-8 \mathrm{MPa}$. A possible explanation for this finding is that roughening of porcelain surface significantly increased the bond strength by increasing the area available for mechanical and chemical retention of composite. This is in agreement with Barbosa et al.(1995) ${ }^{[25]}$. However, mechanical roughening is unfavorable clinically since it damages the porcelain surface permanently by removing the glazed surface and thus porcelain fracture during debonding may occur. This is assured by Kao and Johnston (1991) ${ }^{[5]}$ and Schmage et al.(2003) $)^{[14]}$.

It was found that $37 \%$ concentration of phosphoric acid produced bond strength $5.5 \mathrm{MPa}$. Phosphoric acid didn't etch porcelain and consequently, unlike hydrofluoric acid it didn't produce physical or topographical changes in the porcelain surface. Instead, the effect of phosphoric acid was to neutralize the alkalinity of the adsorbed water layer and as a result enhancing the activity of applied silane primer. This was in agreement to Kao, et al (1988) $)^{[4]}$, Nebbe and Stein (1996) ${ }^{[2]}$, Bourke and Rock $(1999)^{[26]}$, Pannes et al $(2003)^{[27]}$ and Bishara et al $(2005)^{[28]}$.

Concerning laser etching, the mean value of shear bond strength was (6.1) Mpa. This value is still within the acceptable clinical range. A reasonable explanation for this was that laser treatment produced 
Egyptian

Orthodontic Journal

irregularities in the porcelain surface represented by elevations and depressions as shown in the SEM photomicrograph (fig6), without changing the porcelain glazed surface texture. This was in accordance to Tasane et al (2004) ${ }^{[29]}$.

The use of sandblasting produced high bond strength between composite resin and porcelain surface (8.1) Mpa. This could be explained by roughening the surface with fine sand particles produces pits and channels which provides mechanical interlocking for composite resin. This was in accordance to Cochran et al (1997) ${ }^{[30]}$, Gillis and Redlich (1998) ${ }^{[31]}$ and Andrease et al (2013) ${ }^{[32]}$. Despite of changing in porcelain surface texture produced by sandblasting it might be of no clinical preference.

Etching with strong acid as 9\% hydrofluoric acid also produced strong bond between the orthodontic brackets and the porcelain surface. This is attributed to dissolving the ceramic matrix of porcelain surface this is in agreement with Roulet, $(1995)^{[33]}$, Chen, $(1998)^{[34]}$ Bishara et al (2005) $)^{[28]}$ Nagayassu et al (2006) $)^{[35]}$, Turkkahranman $(2006)^{[36]}$, Kyung et al(2008) ${ }^{[37]}$, Trakyali et al (2009) ${ }^{[38]}$ and Magali et al (2011) ${ }^{[39]}$ Hydrofluoric acid produces some surface dullness on porcelain surface which should be taken in consideration.

The highest incidence of porcelain fracture during debonding was observed in diamond bur group in both ceramic and metal sub groups. This was in agreement with Lacy et al (1988) ${ }^{[40]}$, Gillis and Redlich $(1998)^{[31]}$ Bourke and Rock (1999) $)^{[26]}$ and Schmage et al (2003) ${ }^{[14]}$, Raed et al (2005) ${ }^{[41]}$, Nagayassu et al (2006) ${ }^{[35]}$ and Karan et al $(2007)^{[17]}$. An explanation was found by Philips (1973) ${ }^{[42]}$ who found a reduction of $50 \%$ in the transverse strength of porcelain with glaze removal so deglazing could weaken the porcelain considerably. Moreover bond strength in this group may exceed the cohesive strength of porcelain with concomitant fracture incidence. This was in agreement with Kao and Johnston $(1991)^{[5]}$ who found that the fracture incidence in porcelain was $70 \%$ when debonding force was more than 90 Newton. On the contrary, no incidence of any porcelain fracture or damage during debonding procedure was recorded among laser or phosphoric acid groups in bonded to both ceramic and metal brackets. 
Egyptian

Orthodontic Journal

\section{CONCLUSION}

Different approaches to bonding orthodontic brackets to porcelain surface have been suggested. Both chemical and mechanical adhesion are considered to improve the bond strength, diamond bur roughening produces the maximum shear bond strength although this may damage the porcelain surface during debonding.

I declare there are no instances of conflict of interest.

\section{REFERENCES}

1. Smith GA, Mclnnes-Ledoux P, Ledoux WR, Weinberg R. Ortho-dontic bonding to porcelain: Bond strength and refinishing. Am JOrthod 1988;94:245-252

2. Nebbe B, Stein E. Orthodontic brackets bonded to glazed anddeglazed porcelain surfaces. Am J Orthod Dentofac Orthop 1996;109:431-436

3. Newman G, Snyder W, Wilson C. Acrylic adhesives for bonding attachments to tooth surfaces. Angle Orthod 1968;38:12-18

4. Kao EC, Boltz KC, Johnston WM. Direct bonding of orthodontic brackets to porcelain laminate veneers. Am J Orthod 1988;94:458-468.

5. Kao EC, Johnston WM. Fracture incidence on debonding of or-thodontic brackets from porcelain veneer laminates. J ProsthetDent 1991;66:631-637.

6. Zachrisson YO, Zachrisson BU, Buyukyilmaz T. Surface preparation for orthodontic bonding to porcelain. Am J Orthod Dento-fac Orthop 1996;109:420-430

7. Roberts-Harry D. Laser in Orthodontics. Br J Orthod 1994;21:308-312.

8. Roberts-Harry DP. Laser etching of teeth for orthodontic bracket placement: a preliminary clinical study. Laser Surg Med 1992;12: 467-470

9. Ariyaratnam MT, Wilson MA, Mackie IC, Blinkhorn AS. A com-parison of surface roughness and composite/enamel bondstrength of human enamel following the application of the Nd:YAG laser and etching with phosphoric acid. Dent Mater1997;13:51-55. 
Egyptian

Orthodontic Journal

10. Hess JA. A SEM study of Nd:YAG laser-induced morphological changes of a porcelain surface. Abstract presented at the North American Academy of Laser Dentistry, Mackinac Island, Michican August 15,1991

11. Artun $\mathrm{J}$ and Bergland S. Clinical trials with crystal growth conditioning as an alternative to acid etch enamel pretreatment. Am J Orthod Dentofac Orthop, 198485:333-340,

12. Suliman AH, Swift EJ, and Prediago J. Effects of surface treatment and bonding agents on bond strength of composite resine to porcelain. J Prosthet Dent1993; 70:118-120.

13. Sant' Anna EF, Monnerat ME, chevitarse O, and Stuani MB. Bonding brackets to porcelain in vitro study. Braz Dent J2002; 13:191-196.

14. Schmage P, Nergiz I, Herrmann W, and Ozcan M. Influence of various surfaces -conditioning methods on the bond strength of metal brackets to ceramic surfaces. Am J Orthod Dent facial Orthop 2003; 123: 540-546.

15. Kussano, Claudia Minami, Gerson Bonfante, José Gilmar Batista, and João Henrique Nogueira Pinto. "Evaluation of shear bond strength of composite to porcelain according to surface treatment." Brazilian dental journal 14, no. 2 (2003): 132-135.

16. Türk, Tamer, Duygu Saraç, Y. Şinasi Saraç, and Selma ElekdağTürk. "Effects of surface conditioning on bond strength of metal brackets to all-ceramic surfaces." The European Journal of Orthodontics 28, no. 5 (2006): 450-456.

17. Karan, Sevinc, Tamer Büyükyılmaz, and M. Serdar Toroğlu. "Orthodontic bonding to several ceramic surfaces: are there acceptable alternatives to conventional methods." Ame J Orthod Dentofac Orthop (2007)132, no. 2: 144-e7

18. Rondell Blakey, and James Mah. Effect of surface conditioning in shear bond strength of orthodontic brackets bonded to temporary polycarbonate crowns. Am J OrthodDentofacialorthop2010; 138:72-8. 
Egyptian

Orthodontic Journal

19. Katamish H, Elias M, El-KaraskiA, and Shehata M. Effect of laser etched dental porcelain on the bond strength of porcelain repair material. New Egy J Med1993; 9: 744-748.

20. Li R, Ren Y, and Han J. Effects of pulsated Nd:YAG laser irradiation on shear bond strength of composite resin bonded to porcelain. Hua Xi Kou Qiang Yi XueZaZhi2000; 18: 377-379.

21. Kyung-Mi An, DDS, MSD, and Dong-Seok Sohn The effect of using laser for ceramic bracket bonding of porcelain surfaces Korean J Orthod. 2008 Aug; 38 (4):275-282. Korean

22. Amal S. Nair, Anil Kumar, Shino P Mathew, G Rajashekar, and $\mathrm{G}$ Dhandapani. Evaluation of surface characteristics and shear bond strength of metal brackets bonded to two different porcelain systems treated with different surface condition methods. J IndOrthodSoc 2012; 46(4):308-315.

23. Newman SM, Dressler KB, and Grenadier MR. Direct bonding of orthodontic brackets to esthetic restorative materials using a silane. Am J OrthodDentofacialOrthop 1984; 86:503-506.

24. Ewoldsen N, Beatty MW, Erickson L and Feely D. Effects of enamel conditioning on bond strength with a restorative light cured glass ionomer, J Clin. Orthod 29:621-624, 1995.

25. Barbosa VLT, Almedia MA, Chevitarses O and Keith O. Direct bonding to porcelain. Am J Orthod Dentofac Orthop, 1995107:159-164,.

26. Bourke BM, and Rock WP. Factors affecting the shear bond strength of orthodontic brackets to porcelain.Br J Orthod1999; 26: 285-290.

27. Pannes DD, Baily DK, Thompson JYand Pietz DM. Orthodontic bonding to porcelain: A comparison of bonding systems. J Prothet Dent 2003; 89: 66-69

28. Bishara SE, Ajlouni R, and Oonsombat C. Bonding orthodontic brackets to porcelain using different adhesives/enamel conditioners: a comparative study. World J Orthod 2005; 6(1):17-24. 
Egyptian

Orthodontic Journal

29. Tasanee tangrungsun, saksamut pormbutra, Chtari Kaewsurlythamrong, Wanna Suchato and pompada Jaochakarasiri. shear bond strength of orthodontic brackets bonded to different preparation of porcelain surface $\mathrm{J}$ of oral laser applications $2004 \mathrm{Vol} 4.1$

30. Cochran D, O' Keefe KL, Turner DT, and Poers JM. Bond strength of orthodontic composite cement to treated porcelain. Am J Orthod Dentofacial Orthop; 1997111:297-300

31. Gillis, I., \& Redlich, M. The effect of different porcelain conditioning techniques on shear bond strength of stainless steel brackets. American Journal of Orthodontics and Dentofacial Orthopedics, (1998).114(4), 387-392

32. Andreas Faltermeier, Claudia Reicheneder, Peter Götzfried, and Peter Proff. Bonding orthodontic ceramic brackets to ceramic restorations: Evaluation of different surface conditioning methods. Materials Sciences and Applications 2013; 4 .7A2.

33. Roulet JF, Soderholm KJ, and Longmate J. Effects of treatment and storage conditions on ceramic /composite bond strength. J Dent Res1995; 74:381-387.

34. Chen JH, Matsummura H, and Atsuta M. Effect of etchant, etching period, and silane priming on bond strength to porcelain of composite resin. Oper Dent1998; 23:250-257.

35. Nagayassu, Marcos Paulo, Luciana Keiko Shintome, Eduardo Shigueyuki Uemura, and José Eduardo Junho de Araújo. "Effect of surface treatment on the shear bond strength of a resin-based cement to porcelain." Brazilian dental journal 17, no. 4 (2006): 290-295.

36. Türkkahraman, Hakan, and H. Cenker Küçükeşmen. "Porcelain surface-conditioning techniques and the shear bond strength of ceramic brackets." The European Journal of Orthodontics 28, no. 5 (2006): 440-443.

37. Kyung-Mi An, DDS, MSD, and Dong-Seok Sohn The effect of using laser for ceramic bracket bonding of porcelain surfaces Korean J Orthod. 2008 Aug; 38 (4):275-282. Korean. 
Egyptian

Orthodontic Journal

38. Trakyalı, G., Malkondu, Ö., Kazazoğlu, E., \& Arun, T. Effects of different silanes and acid concentrations on bond strength of brackets to porcelain surfaces. The European Journal of Orthodontics, (2009).31(4), 402-4060.

39. Magáli Beck Guimarães Helen Fernandes Lenz a Rodrigo Salbego Bueno Micéli Beck Guimarães Blaya Luciana Mayumi Hirakata. Orthodontic bonding to porcelain surfaces.Rev OdontoCienc2012; 27(1):47-51

40. Lacy AM, LaluzJ, Watanabe LG, and Dellinges M. Effect of porcelain surface treatment on the bond to composite .J Prothet Dent 1988; 60:288-291.

41. Raed Ajlouni, Samir E. Bishara, Charuphan Oonsmbat, manal Soliman and John Laffon. The effect of porcelain surface conditioning on bonding orthodontic brackets. Angle Orthod 75:858-864, 2005.

42. Phillips Rw. Science of dental materials. W.B. Saunders Co. Philadelphia. London. Toronto. Seventh edition: 537-540, 1973. 